\title{
DO ESTADO AUTORITÁRIO AO ESTADO BENFEITOR: CONSIDERAÇÕES EM TORNO AO ESTADO DE BEM-ESTAR SOCIAL CONTEMPORÂNEO ${ }^{1}$
}

\author{
Leno Francisco Danner (UFR) ${ }^{2}$
}

leno_danner@yahoo.com.br

Resumo: defende-se, neste artigo, que se está assistindo a uma reconsideração positiva do papel do Estado em relação à vida social e à organização econômica, no sentido de que a política democrática e as funções redistributivas, compensatórias e interventoras enfeixadas no Estado estão sendo afirmadas, por diferentes grupos da sociedade, por partidos políticos e mesmo por intelectuais, como as forças diretivas da evolução social e da organização sócio-econômica. Com isso, esse papel positivo do Estado, depois de um longo tempo de ataque e de desestruturação a ele levados a efeito pelas posições neoliberais, orienta-se para o fato de que a pacificação das mazelas sociais geradas em termos de economia capitalista, juntamente com o direcionamento político da vida coletiva tendo por base o reforço da participação democrática cidadã (com vistas a evitar-se o caráter autoritário e a autonomia do Estado e dos partidos políticos frente à sociedade civil), passam a dar a tônica do desenvolvimento de nossas sociedades - fato que a crise econômica mundial atual torna ainda mais premente. O Estado, nesse sentido, é novamente o cerne da própria constituição democrática da sociedade, devendo ser afirmado nesse seu papel e nas lutas de movimentos sociais e de iniciativas cidadãs por mais democracia política, justiça social e reconhecimento cultural.

Palavras-chave: Estado de Bem-Estar Social; Neoliberalismo; Esquerda; Evolução Política da Sociedade.

\footnotetext{
${ }^{1}$ Recebido: 13-12-2013/Aprovado: 14-03-2014/Publicado on-line: 08-09-2014.

${ }^{2}$ Leno Francisco Danner é Professor Adjunto na Universidade Federal de Rondônia, Porto Velho, RO, Brasil.
} 


\section{CONSIDERAÇÕES INICIAIS}

Pode-se dizer que, na teoria política contemporânea de um modo geral, a pergunta pelas tarefas e pelos limites do Estado deu a tônica das investigações e das disputas teóricopráticas em torno à compreensão do sentido seja do processo político como um todo, seja da organização administrativa do Estado ${ }^{3}$. De um lado, tal situação deveu-se, no contexto das sociedades desenvolvidas, à crise do Estado de bem-estar social (Welfare State), tanto em seu viés econômico quanto em seu viés psicossocial ${ }^{4}$; de outro lado, a hegemonia neoliberal e sua proposta de enxugamento das funções administrativas condensadas pelo Estado impulsionou (e talvez esse tenha sido seu único fator positivo) um juízo avaliativo acerca de se efetivamente pode-se prescindir de um Estado com funções interventoras e compensatórias ampliadas, não obstante possíveis consequências negativas frente à clientela por ele englobada 5 .

Quer dizer, neste último caso, se o crescimento do clientelismo e dos processos de racionalização social conduzidos via Estado, para não mencionar-se uma suposta ineficiência econômica originada de suas funções interventoras, regulatórias e compensatórias, representam um problema seja para a integridade dos mundos da vida, seja para a efetividade de uma esfera pública que é crítica do poder, colocando em xeque, sob muitos aspectos, o sucesso desse

\footnotetext{
${ }^{3}$ cf.: HAYEK 1988, Vol. II; HAYEK 1995; NOZICK 1991; OFFE 1984; OFFE 1989; BOBBIO 1997; HABERMAS 1997; HABERMAS 2000; HABERMAS 2001b; HABERMAS 2002b; GIDDENS 1996; GIDDENS 2000; GIDDENS 2001; RAWLS 2003.

${ }^{4}$ cf.: HABERMAS 2001a, Vol. II, p. 491-495; HABERMAS 2001b, p. 22; HABERMAS 2002a, p. 502; OFFE 1984, p. 375; GIDDENS 1996, p. 175; RAWS 2003, § 41-42, p. 195-197

${ }^{5}$ cf.: HABERMAS 2001b, p. 25; OFFE 1984, p. 243-244; OFFE 1987, p. 73 e seguintes; MACPHERSON 1991, p. 30-32
} 
mesmo Estado em termos de estabilização social e de garantia da consistência de um processo de democratização política do poder ${ }^{6}$, por outro lado a diminuição dos processos de integração material daqueles indivíduos e grupos excluídos do processo produtivo, que é uma tônica da realpolitik ocidental desde a década de 1980, lança um contundente desafio no que tange à dissolução do aparato de seguridade social e de garantia dos processos de integração material que a rigor o Estado contemporâneo congrega em si, para não falar-se do caráter problemático do próprio abandono progressivo do controle estatal em relação à esfera econômica (que também é um ponto fundamental da realpolitik ocidental a partir da década de 1980) ${ }^{7}$.

Nesse sentido, o argumento defendido neste trabalho consistirá em que assiste-se, desde a última década do século XX, a uma reconsideração positiva - e que intensifica-se cada vez mais - do papel do Estado em suas tarefas de orientação da economia e de pacificação dos problemas sociais enfrentados pela sociedade civil de uma maneira geral, o que significa dizer que as funções de intervenção econômica (organização e domesticação da economia capitalista) e de estabilização material (integração das classes sociais dependentes do mercado de trabalho) passam a ser o verdadeiro núcleo de atuação e de legitimidade da política democrática, a ser assumido em sua efetividade pelo Estado. Com isso, tem-se um segundo ponto importante, no que diz respeito à análise do Estado contemporâneo: tivemos a solidificação de uma cultura democrática que, se por um lado é crítica

\footnotetext{
${ }^{6}$ cf.: HABERMAS 2001a, p. 494-495, e p. 515; WHITE 1995, p. 113-119

7 cf.: HABERMAS 1997, p. 42; BRAVERMAN 1987, p. 319-340; KATZ 1995, p. 60-98; GIDDENS 1996, p. 164-169
} 
do autoritarismo do poder em suas mais diversas manifestações, por outro lado percebe e afirma esse mesmo poder congregado pelo Estado como um poder pacificador das mazelas sociais geradas basicamente pela desagregação e pelos déficits de instituições sociais, políticas, econômicas e culturais historicamente presentes no solo democrático. $\mathrm{O}$ Estado contemporâneo - esse é nosso argumento - apresenta um aspecto claramente construtivo, marcado pela domesticação de qualquer forma de poder selvagem (econômico, cultural, político, etc.) e pela garantia de uma integração social e cultural de todos os indivíduos e de todos os grupos que efetivamente fazem parte da sociedade. O Estado contemporâneo, assim, já não é mais entendido apenas enquanto monopolizando o exercício da violência legítima (na verdade, a violência do Estado contra a sociedade civil é geralmente percebida como ilegítima), já não é mais entendido enquanto Estado guarda-noturno pura e simplesmente, marcado por um autoritarismo estrutural em sua relação com os movimentos sociais e com as iniciativas cidadãs, mas sim como sendo responsável pela estruturação da sociedade de uma maneira geral e pela garantia do bem-estar social e individual em particular, como o centro da política democrática, direcionado à realização da justiça social e devendo ser perpassado por uma cada vez mais sólida democratização política do poder, aproximando-se, assim, da sociedade civil e de seus clamores por democracia política, justiça social e reconhecimento cultural.

Minhas reflexões, neste artigo, são um tanto genéricas, no que tange à defesa do argumento de que estamos vivenciando uma reafirmação do papel diretivo, regulatório e compensatório do Estado, de que estamos presenciando uma defesa cada vez mais intransigente, diante da atual cri- 
se socioeconômica, do modelo de Estado de bem-estar social; de que somos contemporâneos de uma necessidade sempre mais premente, por parte de iniciativas cidadãs e de movimentos sociais os mais diversos, e mesmo em vários partidos políticos, desse modelo de Estado ampliado, que passa a ser entendido como o centro dinamizador de uma sociedade democrática, como uma esfera inultrapassável quando se pensa na consecução bem-sucedida de processos de justiça sociopolítica e de reconhecimento cultural e sua extensão a todos os âmbitos da sociedade. Ainda que genéricas, tais reflexões encontram respaldo, por exemplo, em vasta literatura da esquerda (a ser citada adiante), que, se em um primeiro momento foi extremamente crítica do processo de racionalização social, de juridificação e de paternalismo enquanto consequências da atuação do Estado de bem-estar social (décadas de 1960 a 1970), por outro lado, a partir da década de 1980, com a gradativa hegemonia teórico-prática do neoliberalismo, passou a empenhar-se em uma revitalização do projeto de Estado de bem-estar social, colocando-se diretamente no apoio da social-democracia europeia, sua propugnadora. Tais reflexões, além disso, encontram respaldo, correntemente, na hegemonia política do Partido dos Trabalhadores no Brasil, há mais de uma década, calcado em uma política social embasada no reforço da participação estatal seja na vida econômica, seja na vida social (com todas as críticas que podem ser feitas a esta programática); na vitória de François Hollande na França, do chavismo na Venezuela, de Néstor e de Cristina Kirchner na Argentina etc.; e, por fim, nos mais diversos movimentos de protesto contra as medidas de austeridade de governos conservadores em várias sociedades europeias (Espanha, Grécia, Itália, Alemanha, Inglaterra etc.), diante da 
atual crise socioeconômica, medidas estas que a rigor apontam, conforme penso, para o enxugamento do Estado de bem-estar social e dos direitos sociais de cidadania, em uma clara fragilização das classes trabalhadoras e daqueles grupos dependentes do assistencialismo público, aos moldes do Estado de bem-estar social.

\section{A JUSTIÇA SOCIAL COMO UMA MIRAGEM: HAYEK SOBRE O SENTIDO DO ESTADO - OU ACERCA DOS FUNDAMENTOS DO NEOLIBERALISMO}

Ora, o ideário neoliberal, calcado na necessidade de um menos Estado e de um mais mercado, teve um efeito contrário ao pretendido, ou seja, ao invés de desacreditar o Estado em suas funções de organização econômica e de integração material, ele reafirmou a centralidade desse mesmo Estado no que tange a tais tarefas, não obstante a incansável luta travada pelos neoliberais contra esse mesmo Estado de bemestar social, que sempre foi seu maior inimigo (tanto quanto as posições social-democratas que o tinham como centro de sua programática teórico-política). Efetivamente, a ideia de que a evolução social, como queria Hayek, ocorreria de um modo espontâneo, sem qualquer mediação institucionalizada de uma maneira geral e da esfera estatal em particular, e mesmo sem qualquer conflito sócio-político definidor dos rumos da mesma, apontava correlatamente para a negação de que haveria uma instituição central com capacidades diretivas da evolução social, bem como para a recusa, ainda no caso do neoliberalismo, de que o poder político fosse instituído enquanto médium de pacificação social, de integração material e, além disso, de estabilização dos embates sociais entre as forças políticas aí hegemônicas. 
A sociedade apareceria, na teoria de Hayek, como um amontoado de indivíduos fechados em si mesmos, cada um buscando seu sucesso material (seja ele entendido da maneira que for); e a dinâmica sócio-evolutiva, se é que podese falar desse modo, seria detonada exatamente por essa persecução individual do interesse pessoal, que, por sua vez, imprimiria a posteriori certo sentido, em termos macroestruturais, a isso que, então, poder-se-ia chamar de evolução social. Mas, esse é o ponto, não existiria um processo de evolução social dirigida institucionalmente e nem, por conseguinte, haveria um órgão ou uma instituição com capacidade para tal, com condições, inclusive, de prever o resultado final do processo e, por isso mesmo, seu caminho, sua direção - e, com isso, a ideia de um Estado organizador da sociedade é, ainda para Hayek, uma ficção, assim como o é a ideia de justiça social (a ser realizada pelas instituições políticas), que, no referido autor, é pura e simplesmente uma miragen (HAYEK 1995, p. 37-42, p. 49-52, p. 61-64).

Estado existe, é bem verdade, e tem funções importantes, mas elas restringem-se, sintetizam-se na garantia de que tal evolução espontânea possa continuar ocorrendo sem a postura intervencionista de uma instituição que não tem o poder nem de visualizar o resultado final de sua atuação e nem, da mesma forma, de organizar o processo evolutivo como um todo, do início ao fim. Por isso, as funções do Estado são aquelas já afirmadas no liberalismo político e econômico clássico, ou seja, proteção da propriedade e garantia da efetividade dos contratos, permitindo uma competição racional e equitativa entre todos os indivíduos e grupos produtivos. Aqui, basta aquele Estado mínimo, caracterizado pela monopolização do exercício legítimo da violência e fundado e restringido ao fomento do direito 
privado, na medida em que tal função seria suficiente para garantir que as forças espontâneas da sociedade pudessem não tanto ser desencadeadas, mas, principalmente, não ser impedidas por qualquer poder pretensamente pacificador, que tivesse um padrão social de organização e de igualdade como orientador de sua ação. No caso do neoliberalismo de uma maneira geral e de Hayek em particular, a evolução social, ao ocorrer por meio de forças espontâneas (por isso, inclusive, a defesa do laissez-faire), por meio das vontades individuais (sem qualquer visão messiânica do todo, como ele repete), confere primazia exatamente aos poderes sociais distribuídos (desigualmente) e assumidos pelos particulares, sendo que, por causa disso, o poder organizador centralizado no Estado perde qualquer paradigma objetivo no que diz respeito seja à organização social, seja à orientação da atuação dessas forças sociais em disputa.

A ideia de uma evolução espontânea da sociedade, com efeito, retira um critério normativo que é importante, fundamental, no meu entender, para a organização das instituições de uma maneira geral e do Estado em particular, a saber, a igualdade substantiva. Quer dizer, uma organização democrática tem por objetivo garantir que o resultado das relações sociais seja equitativo para todos e, em especial, para as posições mais débeis - avalia-se tais relações pelos resultados que elas possam gerar para todos. $\mathrm{O}$ neoliberalismo, ao contrário, por meio da ideia de evolução espontânea da sociedade, nega que o resultado possa ser tanto o critério de afirmação de um poder organizador quanto o paradigma discriminador da atuação dessas instituições e do modo como as forças sociais relacionam-se entre si. $\mathrm{O}$ neoliberalismo, nesse sentido, preocupa-se com o ponto de partida, em particular com a garantia administrativa de que o processo 
como um todo é determinado de modo não-intencional, o que pressupõe ampla mobilidade de ação por parte dos indivíduos e dos grupos - e o fomento institucional disso, através da justiça comutativa e contratual, mas não, como seria o caso no primeiro ponto acima, da justiça distributiva.

No caso do neoliberalismo, o individualismo (no sentido do conceito lockeano de propriedade - vida, liberdade e bens) e a garantia de um ponto de partida equitativo para todos seriam condições suficientes para garantir-se a justiça do resultado final e, com isso, tornariam injustificada a intervenção do Estado a posteriori na repartição do produto social, direcionada à correção das desigualdades sociais, mesmo que elas tenham se originado desse ponto de partida equalizado. Os direitos individuais fundamentais ao estilo lockeano, ao exigirem apenas um ponto de partida equitativo, ou seja, ao reivindicarem os mesmos direitos e o mesmo tratamento formal (em termos de igualdade jurídico-constitucional, abstrata e na forma da lei) para todos os indivíduos por parte das instituições, delimitam uma posição moral que, ao negar a existência de estruturas sociais que poderiam influenciar o processo de produção e, com isso, a distribuição final do produto alcançado, eleva esse mesmo individualismo ao critério orientador das instituições políticas e sociais (HAYEK 1987, p. 38-47; 1985, Vol. II, p. 01-11). Aqui, tendo-se por base os direitos individuais do bourgeois (sintetizados pelo conceito lockeano de propriedade, com um sentido eminentemente economicista), tais instituições passam a ser percebidas a partir do máximo de liberdade - ou não - que conferem a cada indivíduo para que este faça o que quiser, em particular, para o que aqui me interessa, a liberdade econômica: a instituição mais justa é 
aquela que menos interfere na ação de cada indivíduo ao buscar seu interesse pessoal, e a mais injusta é aquela que mais põe obstáculos a cada indivíduo no que diz respeito à persecução de seus objetivos ${ }^{8}$. Note-se, em relação a isso, que, para Hayek, a evolução social, que acontece espontaneamente, por parte de indivíduos que não têm nenhuma visão profética ou holística do todo, é definida a partir das relações de produção - daí a importância, ainda no referido autor, do máximo de liberdade para cada indivíduo e a correlata negação de um Estado interventor e compensatório (já que Hayek não crê na existência de estruturas sociais que, influenciadas pelo poder de classe, possam definir desigualmente essa mesma evolução e seus resultados).

Ora, no momento em que se concebe que existem apenas indivíduos que agem uns frente aos outros buscando seu interesse pessoal, negando-se, por conseguinte, a existência de processos sociais e de instituições que, marcadas por relações de poder advenientes de grupos hegemônicos no seio da sociedade (e que não são necessariamente grupos econômicos), acabam determinando poderosamente o re-

\footnotetext{
${ }^{8}$ Que fique claro, entretanto, que o liberalismo clássico não restringe-se apenas a uma posição economicista, senão que possui - por causa da afirmação dos direitos individuais fundamentais e da contraposição entre esfera privada (que diz respeito apenas ao indivíduo e às suas escolhas pessoais) e esfera pública - uma radicalidade no nível cultural que não pode ser ignorada. É nesse sentido, inclusive, que não concordo com todas as críticas de Hegel e de Marx ao liberalismo clássico, que enfatizam o caráter deturpado do individualismo. Como acredito, no nível da cultura e mesmo no nível da política, a ênfase nos direitos individuais fundamentais e na diferenciação (e quase contraposição) entre esfera privada e esfera pública adquire um traço altamente explosivo e revolucionário frente à tradição e às instituições ossificadas, em favor de cada indivíduo. De todo modo, aqui, neste trabalho, o meu objeto de crítica diz respeito à ideia de liberdade econômica que, no caso do liberalismo clássico, contrapõe-se radicalmente à ideia de justiça social, exatamente por não reconhecer a existência de estruturas sociais, de déficits institucionais e de relações de poder que podem solapar a equidade do processo produtivo e em termos de distribuição da riqueza socialmente produzida, alargando-se para mais áreas da vida social (para a esfera política, por exemplo). E essa posição é reafirmada pelo neoliberalismo de uma maneira geral e por Hayek em particular. Também não concordo com a defesa neoliberal de uma autorreferencialidade da esfera econômica, caudatária do liberalismo clássico.
} 
sultado final do processo de produção da riqueza social (para não falar-se também do acesso ao poder político), tem-se condições, como o faz Hayek, de defender que as desigualdades sociais podem, no máximo, ser atribuídas ao maior ou menor desempenho de cada indivíduo frente aos demais, mas nunca de que tais déficits na distribuição do produto social foram ocasionados por problemas institucionais ou pela organização classista da sociedade, determinados pelas lutas de poder que perpassam a constituição e a evolução social (e a serem percebidas em sua especificidade a partir de cada caso e por meio de pesquisas sociológicas). Então, pelo fato de não serem déficits institucionais, no que tange à produção e à distribuição da riqueza social, não se pode, por meio do Estado interventor e compensatório (Welfare State), instaurar-se um processo de correção dessas desigualdades através da distribuição da riqueza social, haja vista que essa riqueza foi produzida por indivíduos que buscavam seu interesse pessoal em sua relação com os demais indivíduos. E, dirá Hayek, se esses indivíduos agiram sob o respaldo da legislação juridicamente afirmada, então não fizeram nada de errado e são senhores legítimos de tudo aquilo que amealharam. Quer dizer, seguindo o raciocínio de Hayek, se negamos que existem instituições e processos sociais, que - conforme a teoria social de índole marxista prejudicam a equidade das relações sociais exatamente pelo fato de que são detonados por instituições políticas que não são imunes aos grupos de poder e aos conflitos de classe presentes na sociedade, também teremos de negar (como o próprio Hayek o faz) que a programática do Estado de bemestar social contemporâneo, calcada na inclusão social dos grupos dependentes do trabalho (inclusão essa que é feita, entre outras coisas, por meio da distribuição de produto so- 
cial), é ilegítima. Com efeito, no ideário neoliberal, tal distribuição violaria o ponto de partida igual que todos os indivíduos teriam em termos de organização da sociedade; mais ainda, tal distribuição do produto social para os menos favorecidos somente seria possível se correlatamente se instaurasse medidas que penalizassem aqueles que mais se dedicaram na persecução de seus interesses pessoais e, por causa disso, enriqueceram em um grau maior.

Hayek, desse modo, elimina as questões distributivas enquanto objeto de consideração do Estado. A justiça social é uma miragem exatamente porque não existe a sociedade estritamente falando, com suas instituições e processos objetivos que configurariam, a partir das relações de poder e das lutas de classe existentes na sociedade (e configuradoras daquelas instituições), a distribuição do produto social e o status quo daí adveniente. O Estado seria liberado de um duplo objetivo, no que tange às tarefas distributivas: de um lado, já não poderia mais intervir na economia a partir de critérios de igualdade substantivos, que orientassem o crescimento econômico; de outro lado, esse mesmo Estado já não necessitaria congregar instituições encarregadas de processos ampliados de distribuição do produto social (HAYEK 1987, p. 48-54; 1985, Vol. II, p. 79-122). Somente existem indivíduos, que buscam seu interesse pessoal, e não a sociedade enquanto totalidade estritamente falando, de modo que um Estado com funções ampliadas, em sentido distributivo, compensatório e regulatório, não faz o mínimo sentido - a própria Margaret Thatcher deixou claro essa posição em uma entrevista do início da década de 1980, enquanto um dos pontos-chave da posição neoliberal em sua 
compreensão do papel do Estado de bem-estar social em suas funções interventoras e compensatórias ${ }^{9}$. Para tais indivíduos, a equiparação em termos de posição inicial seria tudo o de que eles precisariam para atingirem seus objetivos por si mesmos, bem como para tornar moralmente justificados esses mesmos objetivos alcançados. Mas, é claro, a questão não é essa, e sim se a própria distribuição do produto social - para os grupos menos favorecidos - seria a miragem, moralmente injustificada pela inexistência de estruturas sociais e políticas perpassadas por desigualdades e conflitos de classe, de que fala Hayek e, portanto, se um Estado de bem-estar social representaria, na medida em que estivesse fundado em tal paradigma, a verdadeira causa da consolidação de grandes focos de desigualdade na sociedade e da própria ineficiência econômica - segundo Offe e Dubiel, o discurso neoconservador, que passou a ganhar fôlego a partir de meados da década de 1970 e que consolidou-se efetivamente a partir da década de 1980 na realpolitik de muitas sociedades ocidentais, procurava associar ineficiência econômica e falta de motivação para o trabalho com a quantidade de benesses oferecida em termos de Estado de bem-estar social, correlatamente ao intervencionismo ampliado deste na esfera econômica ${ }^{10}$. Importante, para este raciocínio liberal, foi a posição hayekiana de que não existem estruturas sociais ou a sociedade enquanto totalidade, enquanto macrossujeito, mas sim apenas indivíduos que buscam, cada um, seu interesse pessoal, destituídos de qualquer visão messiânica do todo. Assim, ainda de acordo com o neoliberalismo, as instituições públicas não teriam

\footnotetext{
${ }^{9}$ cf.: HARVEY 2008, p. 31; HABERMAS 2000, p. 82.

${ }^{10}$ cf.: OFFE 1984, p. 236-257; DUBIEL 1993, p. 06 e seguintes.
} 
legitimidade no momento em que direcionam sua atuação a uma suposta e falaciosa correção de estruturas sociais, políticas e econômicas causadoras de desigualdades entre os indivíduos e os grupos, influenciadas e delimitadas pelas lutas de classe que perpassam cada sociedade. Não existem estruturas sociais e nem lutas de classe, argumenta Hayek, o que torna o papel distributivo, compensatório e corretivo do Estado de bem-estar social totalmente ilegítimo - a justiça social como uma miragem da esquerda e de grupos marginalizados da sociedade, que não levaram a sério a meritocracia do trabalho ou que foram perdedores nessa mesma meritocracia (BUTLER 1987, p. 94-108). Entretanto, a história posterior do neoliberalismo e mesmo muitas posições teórico-políticas afetadas pela crise do Estado de bemestar social (por exemplo, os partidos trabalhistas e a socialdemocracia europeia), em relação a isso, deixaram claro que o papel do Estado não poderia ser desconsiderado pura e simplesmente, nas tarefas acima citadas.

\section{A REVIRAVOLTA DA ESQUERDA NÃO-COMUNISTA OCIDENTAL ${ }^{11}$ E A AFIRMAÇÃO DO ESTADO DE BEM-ESTAR SOCIAL}

De fato, neste último caso, basta analisar-se a reviravolta de pensamento dada por muitos pensadores ligados à esquerda ocidental, desde a década de 1980, para ter-se uma noção

\footnotetext{
${ }^{11}$ Para este trabalho, entenderei o conceito de uma esquerda ocidental não-comunista como sendo significado pela ênfase em um Estado forte, interventor na esfera econômica e realizador de direitos sociais de cidadania. Teoricamente, os pensadores de esquerda reconhecem a existência de estruturas sociais e/ou de lutas de classe que perpassam a dinâmica evolutiva, a produção da riqueza na esfera econômica e a constituição do Estado em sua relação com a democracia. Nesse sentido, enquadrarei pensadores como Rawls, Habermas, Bobbio, Offe, Honneth etc. como fazendo parte da referida esquerda teórica ocidental não-comunista - embora não me detenha em uma fundamentação mais detalhada dela.
} 
clara do grande problema que seria a desestruturação do modelo representado pelo Estado de bem-estar social. $\mathrm{O}$ tom alarmista e a contraposição que, por exemplo, Bobbio, Offe, Habermas e Rawls explicitam em seus trabalhos frente à hegemonia da programática neoliberal, conjugado à defesa de que as questões públicas ligadas à distribuição da riqueza produzida socialmente recebessem a devida atenção em termos de planejamento estatal, de que elas fossem realizadas efetivamente como condição do desenvolvimento e da paz sociais, denotam exatamente o quanto a esquerda, desde essa década de 1980, encontrou seu campo de luta e sua programática na defesa e na necessidade de prossecução do modelo social-democrata representado pelo Estado de bem-estar social ${ }^{12}$; ou, no caso de Rawls, na afirmação de um liberalismo social aos moldes da social-democracia europeia, caracterizado pela garantia de padrões mínimos de igualdade material e por um Estado que possui papel ativo na gestão da esfera econômica e na integração social, e contraposto - também ele - ao neoliberalismo (RAWLS 2002; 2003). Com efeito, tanto muitos desses pensadores de esquerda quanto muitos movimentos sociais gestados durante os anos 1960, claramente apontavam, no período anterior à década de 1980, para o caráter autoritário e paternalista de muitas instituições democráticas e, dentre elas, do Estado de bem-estar social - aproximando-se, em muitos casos, das críticas neoconservadoras ao Estado de bem-estar social. No caso de Habermas, por exemplo, começando com Mudança Estrutural da Esfera Pública e chegando-se à Teoria da Ação Comunicativa, a crítica à tecnocracia e à subversão da esfera públicopolítica tinha como alvo esse Estado de bem-estar autoritá-

${ }^{12}$ cf.: OFFE 1984; OFFE 1989; HABERMAS 1997; HABERMAS 1991; BOBBIO 1997. 
rio e paternalista, que seria o grande promotor da evolução social contemporânea e que congregaria em si as tarefas de dinamização e de legitimação do desenvolvimento econômico em seu processo de acumulação privada da riqueza socialmente produzida e a estabilização social dos déficits gerados pela modernização econômica no mundo da vida das classes dependentes do trabalho (HABERMAS 1970, p. 49). Nesse sentido, a planificação racional da sociedade por parte do Estado e o solapamento da esfera público-política levado a efeito pelos partidos políticos profissionais, enquanto processos correlatos, seriam os grandes problemas que acirrariam, conforme Habermas, o caráter fetichista da democracia de massas - ou seja, a democracia de massas (concebida, nesse momento, em um sentido como que negativo) era uma conseqüência do Estado de bem-estar social organizado com vistas à promoção e à legitimação do processo privado de acumulação da riqueza socialmente produzida e, aqui, mantenedor da estrutura de classes no que tange à organização da sociedade, que somente seriam possíveis por meio da anulação do potencial de crítica de uma sociedade civil altamente politizada, isto é, nas palavras de Habermas, no momento em que a sociedade civil fosse despolitizada administrativamente ${ }^{13}$.

Ora, essa reviravolta de pensamento da esquerda, de que falei acima, pode ser percebida em Habermas, a partir da década de 1980, no fato de que, para ele, o desafio lançado pelo neoliberalismo hegemônico em seu combate ao Estado de bem-estar social exigiria das forças teóricopolíticas contrárias - a esquerda de uma maneira geral exatamente a defesa desse mesmo Estado de bem-estar soci-

${ }^{13}$ HABERMAS 1986, p. 328-329; MCCARTHY 2001, 298-299; HONNETH 2007, p. 129-148. 
al tanto em suas funções de regulação econômica quanto em suas funções de integração material. Quer dizer, paradoxalmente, no caso de Habermas, se antes o Estado de bemestar social seria percebido como emperrando a constituição democrática da sociedade, como solapando a integridade político-cultural da democracia de massas, agora, a partir da década de 1980, o Estado de bem-estar social assumiria a função de núcleo organizador da democracia de massas, tornando-se sua condição de possibilidade (no sentido de garantir a efetividade da mesma). Trata-se, no caso desse pensador, de uma mudança deveras impressionante ${ }^{14}$. E, por isso, agora, já não se poderia abdicar do Estado de bemestar social, senão que ele seria modelo para todas aquelas sociedades que ainda não teriam alcançado esse grau de desenvolvimento. Habermas disse isso em 1984 de maneira enfática:

[...] as instituições do Estado de bem-estar social constituem, não menos que as estruturas do Estado constitucional democrático, um impulso de desenvolvimento do sistema político em relação ao qual não existe nenhuma alternativa em sociedades semelhantes à nossa seja no que diz respeito às funções preenchidas pelo Estado de bemestar social, seja no que tange às exigências normativas às quais ele faz jus. ${ }^{15}$

\footnotetext{
${ }^{14}$ Isso não significa, entretanto, que as críticas tecidas por Habermas ao projeto social-democrata de Estado de bem-estar social (tecnocracia, subversão da esfera público-política, juridificação, paternalismo de bem-estar) tenham sido abandonadas. Como procurei defender em minha tese doutoral em filosofia, trata-se, no caso do referido autor, da defesa de uma continuidade reflexiva do projeto social-democrata de Estado de bem-estar social, temperado com a instauração de focos de democracia radical, que, ao aproximar a estrutura administrativa, os partidos políticos profissionais e a esfera público-política instaurada pelos meios de comunicação de massa aos movimentos sociais, às iniciativas cidadãs e às esferas públicas informais por eles desenvolvidas, reduz a possibilidade de que o poder do Estado e a hegemonia dos partidos políticos profissionais transformem a participação democrática em puro fetiche, oferecendo, inclusive, um contraponto à mídia de massas. Sobre isso, conferir: (DANNER 2011).

${ }^{15}$ HABERMAS 2001b, 23. Cf., ainda: OFFE 1991, Vol. II, p. 127; FLICKINGER 2003, p. 34-35.
} 
A posição de Habermas, conforme penso, é sintomática de uma tendência geral que mudou o foco da esquerda ocidental (e o próprio Habermas também foi responsável por isso), a saber, de uma crítica radical ao Estado, feita, em muitos casos, de um modo muito pueril, superficial, que o associava pura e simplesmente ao autoritarismo e o concebia como uma instituição reprodutora de relações de clas$\mathrm{se}^{16}$, passou-se a defender que o Estado é o centro diretivo da sociedade, o instrumento por excelência de regulação econômica e de estabilização social, centro político esse que não poderia ser abdicado, mas sim reformado. A esquerda, assim, se por um lado ainda mantém a importante defesa de uma maior aproximação entre movimentos sociais e iniciativas cidadãs frente ao Estado e aos partidos políticos, por meio de focos de democracia radical (o que denota sua desconfiança frente aos poderes burocráticos institucionalizados), como condição da efetividade da democracia sóciopolítica, por outro lado começou a afirmar veementemente a premência de salvar-se, de reafirmar-se e mesmo de aprofundar-se ainda mais a política social, os processos de regulação econômica e, principalmente, de integração social a rigor enfeixados pelo Estado de bem-estar social. Para esta nova esquerda (no sentido de afirmação de uma nova mentalidade), o Estado de bem-estar social é um pilar fundamental no diz respeito à sua programática teórico-política, no que se refere à resolução dos problemas originados pela modernização capitalista, agora dimensionada ao mundo todo por meio do processo de globalização econômica.

Desde então, por conseguinte, a programática de esquerda, de uma maneira geral, seja na Europa ocidental (em

${ }^{16}$ cf.: POULANTZAS 1981; MILIBAND 1972; MACPHERSON 1978; MACPHERSON 1991. 
que a tradição de esquerda, social-democrata, apoiada historicamente nos movimentos de trabalhadores e na força dos sindicatos trabalhistas, sempre foi muito forte e direcionada à realização da justiça distributiva via Estado de bemestar social) ${ }^{17}$, seja nos países latino-americanos (nos quais o processo de democratização da sociedade ainda está em sua fase como que inicial, haja vista que, devido a constantes golpes militares ao longo do século XX, a consolidação da democracia nesta região data de no máximo trinta anos ou menos) (CARDOSO 2012), seja mesmo na América do Norte, berço do keynesianismo do Partido Democrata ${ }^{18}$, tem na defesa e na prossecução do Estado de bem-estar social seu cerne. Essa esquerda teórico-política passou a focar diretamente na defesa de um modelo de Estado ampliado, que responsabiliza-se pelo controle e pelo fomento da economia ao mesmo tempo em que busca promover socialmente padrões de integração material que de fato garantam o mínimo social necessário (utilizando palavras de Rawls) (RAWLS 2002, p. XV-XVI; 2003, § 17, p. 85) para a satisfação das necessidades básicas de todos os cidadãos (HARVEY 2008, p. 19-21). E o mais importante estaria em que as políticas de integração material seriam dependentes desse controle estatal da esfera econômica, no sentido de evitar que as desigualdades ali surgidas e reproduzidas ao longo do tempo desintegrassem a sociedade a um ponto tal que esta já não conseguiria afirmar padrões mínimos de igualdade entre todos e nem um poder político pacificador das mazelas sociais (exatamente porque esse poder, em tal

\footnotetext{
${ }^{17}$ cf.: ABENDROTH 1973; OFFE 1996; HABERMAS 1991; HABERMAS 2009; GIDDENS 2001.

${ }^{18}$ cf.: KOLAKOWSKI 1999; HARRINGTON 1999; HOOK 1999.
} 
situação, já não seria democrático, mas sim plutocrático), garantindo a efetividade da democracia política.

Nesta situação em que a defesa do Estado de bem-estar social passa a ser o baluarte da esquerda teórico-política, explicita-se, enfim, a reorientação teórico-política dos partidos, dos grupos sociais e dos intelectuais herdeiros da tradição marxista e ligada aos movimentos proletários no Ocidente: para uma grande parte deles, a luta política direciona-se à necessidade de prossecução do Estado de bemestar social, à domesticação da economia capitalista por meio do Estado e, com isso, à realização ampliada dos direitos sociais de cidadania, correlatamente à instauração de processos ampliados de democratização política do poder, aproximando-se Estado e partidos políticos à sociedade civil. Porém, nesta situação pode-se também (e até principalmente) perceber a mudança de mentalidade democrática que, conforme meu argumento inicial, inspirou e, atualmente, inspira a onda de protestos contra as medidas de austeridade política adotadas por muitos países ocidentais como forma de evitar-se a crise econômico-financeira hodierna e retomar-se o crescimento, em um momento em que o desemprego atinge níveis verdadeiramente astronômicos correlatamente à deterioração do padrão de vida de grandes parcelas das populações dessas sociedades (pense-se, nesse caso, no modelo exemplar de bem-estar social, material, que a Europa tradicionalmente representaria ontem e, hoje, o crescimento do desemprego estrutural nesse mesmo continente) - deterioração da qualidade de vida e desemprego estrutural que são, em muitos aspectos, acirrados por essas medidas de austeridade, em que o Estado retira-se cada vez mais da vida social, diminui cada vez mais os investimentos políticos no que tange à integração social, como forma de 
favorecer o laissez-faire econômico. Inclusive, o crescimento dos protestos sociais contra o neoliberalismo e, assim, a consolidação de uma mentalidade abertamente a favor do Estado de bem-estar social explicariam a retomada da hegemonia da esquerda partidária em muitas sociedades ocidentais - Brasil, Estados Unidos, França, etc.

\section{O ESTADO COMO INSTITUIÇÃO SOCIALMENTE VINCULADA: UMA TENDÊNCIA DA POLÍTICA DEMOCRÁTICA HODIERNA}

Com efeito, essa reconsideração do papel do Estado na vida social, marcada pela apreciação favorável, pela avaliação positiva que os cidadãos fazem do Estado em matéria de política social e econômica, constitui, no meu entender, uma novidade para nossas sociedades. E constitui uma novidade pelo fato de que, tradicionalmente, a exclusão de grandes parcelas da população no que se refere à distribuição da riqueza social e mesmo em relação à participação política efetiva deu a tônica, no caso da América Latina, da constituição dos regimes democráticos, que, por isso mesmo, em muitos aspectos, foram marcados por uma integração social seletiva, excludente e até violenta, correlatamente à constituição de uma estrutura estatal e partidária autoritária e paternalista, bem como de uma esfera público-política eminentemente monopolizada por poucos grupos de comunicação. Por conseguinte, aqui, neste vasto rincão, o processo de democratização foi tradicionalmente perpassado por falhas gritantes, que imprimiam no próprio seio do Estado as desigualdades de classe e o autoritarismo no que se refere à atuação do poder concentrado por ele frente à sociedade civil. A ideia de um Estado guarda-noturno e paternalista, que ostenta, em uma mão, o chicote impiedoso 
e, na outra mão, o afago próprio do cabresto, marcou efetivamente a constituição de nossas sociedades e, nesse aspecto, a mentalidade popular em relação ao Estado, se por um lado dificilmente se desprendeu daquele sentido de paternalismo, por outro lado nunca viu com bons olhos aquele Estado que, com o relho, sabia impor a vontade caudilhista de seus líderes, calando os anseios populares de mais participação e de justiça social (DE VITA 2002).

Mas grande parte dessa imagem foi feita em pedaços depois destes anos de democratização, em que movimentos sociais e iniciativas cidadãs, escorados em um maior desenvolvimento educacional e contando com a universalização dos meios de comunicação e com novas formas de resistência e de politização por eles possibilitadas, afirmam seus direitos políticos de participação e a necessidade tanto de moralizar-se a res publica quanto de aproximar-se os anseios e as vozes que ecoam da sociedade civil ao poder congregado no Estado e aos atores políticos sintetizados nos partidos políticos profissionais. Some-se a isso a consolidação de um vasto (mesmo que, sob muitos aspectos, paternalista e insuficiente) programa político de assistência social, que é marcante na evolução de nossa sociedade e decisivo na legitimação do poder político e em termos de hegemonia dos partidos políticos, e pode-se perceber o por que de, no Brasil, hodiernamente, não poder ser afastada da pauta política e da agenda institucional a realização de amplos processos de integração material correlatamente ao incentivo e ao controle permanentes do Estado na vida econômica, pelo menos em alguma poderosa medida.

$\mathrm{Na}$ Europa e nos Estados Unidos, de todo modo, a crise econômica mundial, na atualidade, resultado de uma hegemonia bem longa de governos neoliberais, que 
reimprimiram o laissez-faire em sua organização econômica e, com isso, restringiram os limites de atuação do Estado, essa crise, como dizia, também força a reconsideração do papel do Estado seja no que diz respeito à regulação da vida econômica, seja no que tange à realização de políticas de integração social ampliadas ${ }^{19}$. A chaga do desemprego estrutural e, aqui, a necessidade de políticas públicas que fomentem o desenvolvimento com emprego - e não o jobless growth (crescimento sem emprego) neoliberal - ou mesmo substitutivos públicos para os grupos que vivem permanentemente sob o flagelo do desemprego estrutural tornaram novamente atual o ideário social-democrata fundado no Estado de bem-estar social. Parafraseando Habermas, se já é difícil conviver com o crescimento das tarefas do Estado, muito mais difícil será viver sem seu poder pacificador das mazelas sociais e interventor na esfera econômica.

Em tudo isso, seja no caso no Brasil, seja no caso da Europa e mesmo nos Estados Unidos, mais e mais cidadãos estão tomando consciência de que somente a retomada de uma política diretiva em relação aos mercados e ao capital financeiro pode oferecer condições para a superação da atual crise econômica e ao desemprego estrutural. Para estes cidadãos, portanto, a política democrática tornou-se novamente um ethos, radicalmente constituinte da sociedade em que vivem, para além do privatismo civil que, no entender de Habermas, por exemplo, teria imprimido muito da dinâmica em termos de constituição das democracias de massa da Europa ocidental no pós-guerra. Nesse sentido, de um lado, os cidadãos sabem separar o sentido do Estado, o papel do Estado na vida social, e as forças políticas que dispu-

\footnotetext{
${ }^{19}$ cf.: HICKS 1999, DUGGAN 2003; BELLAMY FOSTER \& MADGOFF 2009.
} 
tam o poder. Aqui, por causa disso, o Estado passa a ser entendido como uma instância fundada em pressupostos normativos importantes, inultrapassáveis, haja vista que seu objetivo é realizar, de um modo equitativo e com base na lisura de seus procedimentos, processos de justiça social e políticas distributivas maximamente inclusivas. Ora, os grupos disputantes do poder, independentemente de sua ideologia, precisam assumir esse compromisso, em termos de condução do Estado - e eles não podem furtar-se à necessidade de justificação pública permanente em relação à sua postura. De outro lado, os cidadãos, ao separar o Estado e os grupos de poder disputantes da legitimidade pública concernente à condução do mesmo, também passam a afirmar seu inalienável direito de fiscalizar a atuação desses grupos, de modo que a res publica possa ser administrada com base em procedimentos justos, equitativos, levando em conta interesses generalizáveis e realizando esse conteúdo normativo ínsito à ideia de justiça social, tudo isso sempre tendo por base processos abertos e permanentes de justificação pública. A política, enquanto atividade diretiva centralizada no Estado e realizada na interação entre partidos políticos profissionais e movimentos sociais e iniciativas cidadãs, torna-se novamente um ethos moral, perpassada, desse modo, por uma compreensão normativa de sua estrutura, de seus instrumentos e de seu objetivo, direcionando-se à efetivação de interesses generalizáveis advenientes da sociedade civil e moralmente fundados. Nela, um ideal de justiça social consolidou-se com consistência, concedendo força a uma mentalidade social e a uma postura teórico-política que veem no Estado e em um Estado de bem-estar social - o núcleo diretivo e organizador por excelência da sociedade, calcado exatamente na promoção da justiça social e perpassado por focos de 
democracia política substantiva.

\section{CONSIDERAÇÕES FINAIS}

Seja em termos da esquerda teórico-política, seja no que tange aos movimentos sociais e às iniciativas cidadãs, uma nova mentalidade e uma nova postura teórico-política marcam a constituição das sociedades democráticas contemporâneas, das últimas décadas do século XX para cá. Como reação às posições neoliberais e às sequelas sociais e políticas provocadas por um grande período de hegemonia neoliberal (da década de 1980 para diante em algumas das maiores sociedades europeias, nos Estados Unidos e, com ênfase na década de 1990, no Brasil e em outros países da América Latina), tem-se progressivamente a afirmação de um Estado ampliado, que, ao mesmo tempo em que regula a produção da riqueza, também responsabiliza-se pela realização de sua distribuição social (ainda que sob critérios mínimos, em muitos casos), em particular protegendo os grupos mais vulneráveis contra as conseqüencias deletérias em termos de desemprego e de falta de condições materiais básicas para a sobrevivência. Para essa esquerda teóricopolítica e para esses movimentos sociais e iniciativas cidadãs, a justiça social é o núcleo normativo organizador da práxis política e definidor do sentido do Estado - um núcleo normativo que a rigor deve ser realizado pelo Estado, perseguido por este.

Com isso, o título deste trabalho - do Estado autoritário ao Estado benfeitor - quer significar exatamente esse diagnóstico de que a política hodierna, ligada a uma mentalidade social eminentemente marcada pela consideração das questões de justiça distributiva e de participação democrática in- 
clusiva dos cidadãos nas instituições, centra-se na defesa e na promoção do Estado de bem-estar social ou, pelo menos, em um Estado com funções ampliadas, distributivas, compensatórias e regulatórias. Esse Estado passa a ser entendido não mais apenas em sua função negativa, enquanto guardanoturno e marcado pelo solapamento da integridade da democracia de massas, mas sim efetivamente como Estado de bem-estar social, força pacificadora das mazelas sociais, centro político diretivo da sociedade, organizador da vida social e disciplinador do poder econômico selvagem. É um elemento novo para a esquerda e para o ethos das sociedades democráticas, haja vista que, tanto em posições radicais da esquerda de até os anos 1980 quanto nos movimentos sociais e estudantis da década de 1960, esse mesmo Estado seria visto fundamentalmente em seu viés autoritário, paternalista, clientelista e classista; de outro lado, ainda neste contexto, muitos grupos que a rigor teriam se retraído ao privatismo civil hoje renegam-no (isto é, renegam o privatismo civil) e passam a afirmar sua cidadania política e seu direito de contribuir na evolução da sociedade em que vivem e mais além. E é uma nova mentalidade que, conforme penso, tem condições de gerar uma postura teórico-política plenamente capaz de influenciar e de fortalecer, de um lado, a atuação dos movimentos sociais e das iniciativas cidadãs frente aos partidos políticos aspirantes ao poder nas sociedades democráticas, fazendo com que a sociedade civil, por meio desses movimentos e dessas iniciativas, organize-se com vistas a orientar a própria atuação dos partidos políticos profissionais, que, em muitas situações, são imunes a esta influência e a este contato. De outro lado, essa nova mentalidade afirmadora do poder pacificador do Estado tem condições de solidificar perenemente a compreensão 
normativa da política e de sensibilizar a atuação das forças políticas para a importância no que tange à realização de padrões de justiça distributiva para todos os indivíduos e grupos sociais, em particular para aqueles mais vulneráveis, e de que isso passa pela afirmação de um Estado com funções regulatórias e interventoras frente à economia, pelo menos em algum aspecto poderoso.

Com efeito, por um lado, conforme acreditam muitos pensadores da própria esquerda, aquela pretensão de um macrossujeito da transformação social que teria uma função política diretiva absolutamente fundamental para uma práxis democrática emancipatória, defendida tão ardentemente pelo marxismo, já não existe no proletariado strictu sensu ${ }^{20}$. Por outro lado, entretanto, é claro que a afirmação, seja pela esquerda teórico-política de uma maneira geral, seja por movimentos sociais e por iniciativas cidadãs, do Estado enquanto centro político diretivo da vida social tem o mérito de chamar a atenção para um centro político diretivo da vida social (contrapondo-se, por conseguinte, à posição neoliberal, que nega a existência e a possibilidade de um centro político diretivo da sociedade), que existe, que é constituído por esse mesmo Estado e no qual os movimentos sociais e as iniciativas cidadãs (com suas pautas plurais), por meio de processos democráticos inclusivos, podem oferecer um complemento à atuação dos partidos políticos profissionais no que tange à condução da evolução social, exigindo que esta aconteça com base em fundamentos normativos e leve em conta interesses generalizáveis caudatários da sociedade civil politizada. Eu acredito, em relação a isso, que a consi-

\footnotetext{
${ }^{20}$ cf.: ABENDROTH 1973, p. 235-236; HABERMAS 1999, p. 79; GIDDENS 2000, p. 12-15; GIDDENS 2001, p. 36-37, p. 46, p. 62.
} 
deração positiva do papel do Estado no que diz respeito à economia e à vida social, e sua afirmação tanto pela esquerda teórico-política quanto principalmente, no meu modo de compreender, pelos movimentos sociais e pelas iniciativas cidadãs veio para ficar e imprimirá, por um longo tempo, por um tempo a perder-se de vista, o próprio direcionamento social da política parlamentar e sua intersecção com focos de democracia radical, aproximando-se poder administrativo-partidário em relação aos movimentos sociais e às iniciativas cidadãs, configurando o próprio Estado e direcionando-o a uma profunda vinculação social da política - ainda que isso dependa muito das constelações de força presentes da própria sociedade e dentro dos partidos políticos - com vistas à realização de padrões mínimos de bem-estar material. Trata-se, assim, de um momento muito auspicioso para a política democrática, calcada em questões de justiça social e distributiva, que está sendo percebida como um elemento fundamental para a evolução social.

\begin{abstract}
: the paper argues that it is possible to perceive a positive reconsideration about the importance of State role on social life and economic organization, in that democratic politics and redistributive, compensatory and interventive functions of the State are affirmed as directive forces of social evolution and socio-economic organization, by many groups of society, political parties and even intellectuals. Therefore, this positive role of the State, after a long time of supremacy of neoliberal positions and its disruption of State, is oriented to pacification of social poverty produced by capitalist economy and to reinforce democratic political participation of citizens (avoiding authoritarianism and autonomy of State and political parties) - something that current economic worldwide crisis makes more preeminent. So, the State is the core of democratic constitution of society itself, again, and it must be affirmed in this position and in the vindications of social movements and citizen initiatives about solid processes of political democracy, social justice and cultural recognition.
\end{abstract}

Keywords: Welfare State; Neoliberalism; Left; Political Evolution of Society. 


\section{REFERÊNCIAS}

ABENDROTH, Wolfgang. Sociedad Antagónica y Democracia Política. Traducción de Manuel Sacristán. Barcelona: Grijalbo, 1973.

BELLAMY FOSTER, John; MAGDOFF, Fred. The Great Financial Crisis: Causes and Consequences. New York: Monthly Review Press, 2009.

BOBBIO, Norberto. O Futuro da Democracia: Uma Defesa das Regras do Jogo. 6a Edição. Tradução de Marco Aurélio Nogueira. Rio de Janeiro: Paz e Terra, 1986.

BRAVERMAN, Harry. Trabalho e Capital Monopolista: a Degradação do Trabalho no Século XX. Tradução de Nathanael C. Caixeiro. Rio de Janeiro: LTC, 1987.

BUTLER, Eamon. A Contribuição de Hayek às Ideias Políticas e Econômicas de Nosso Tempo. Tradução de Carlos dos Santos Abreu. Rio de Janeiro: Instituto Liberal, 1987.

CARDOSO, Fernando Henrique. A Soma e o Resto: Um Olhar sobre a Vida aos 80 Anos. Rio de Janeiro: Civilização Brasileira, 2012.

DANNER, Leno Francisco. Habermas e a Ideia de Continuidade Reflexiva do Projeto de Estado Social: da Reformulação do Déficit Democrático da Social-Democracia à Contraposição ao Neoliberalismo. 2011. 206 p. Tese (Doutorado em Filosofia) - Pontifícia Universidade Católica do Rio Grande do Sul, 2011.

DE VITA, Álvaro. Sociologia da Sociedade Brasileira. São Paulo: Ática, 2002. 
DUBIEL, Helmut. Qué es Neoconservadurismo? Introducción y Traducción de Agapio Maestre. Barcelona: Editorial Anthropos, 1993.

DUGGAN, Lisa. The Twilight of Equality? - Neoliberalism, Cultural Politics, and the Attack on Democracy. Boston: Beacon Press, 2003.

FLICKINGER, Hans-Georg. Em Nome da Liberdade: Elementos para a Crítica do Liberalismo Contemporâneo. Porto Alegre: EDIPUCRS, 2003.

GIDDENS, Anthony. Para Além da Esquerda e da Direita: o Futuro da Política Radical. Tradução de Alvaro Hattnher. São Paulo: Editora da UNESP, 1996.

- A Terceira Via: Reflexões sobre o Impasse da SocialDemocracia. Tradução de Maria Luiza X. de A. Borges. Rio de Janeiro: Record, 2000.

- A Terceira Via e Seus Críticos. Tradução de Ryta Vinagre. Rio de Janeiro: Record, 2001.

HABERMAS, Jürgen. Toward a Rational Society: Student Protest, Science and Politics. Translated by Jeremy J. Shapiro. Boston: Beacon Press, 1970.

- Perfiles Filosófico-Políticos. Traducción de Manuel Jiménez Redondo. Madrid: Taurus, 1986.

- Problemas de Legitimación en el Capitalismo Tardio. Traducción de José Luis Etcheverry. Madrid: Ediciones Cátedra, 1999.

- Teoría de la Acción Comunicativa (T. 2): Crítica de la Razón Funcionalista. Traducción de Manuel Jiménez Re- 
dondo. Madrid: Taurus, 2001a.

. Ensayos Políticos. Traducción de Ramón Garcia Cotarelo. Barcelona: Ediciones Península, 1997.

- Diagnósticos do Tempo: Seis Ensaios. Organização e Tradução de Flávio Beno Siebeneichler. Rio de Janeiro: Tempo Brasileiro, 2001b.

. O Discurso Filosófico da Modernidade: Doze Lições. Tradução de Luiz Sérgio Repa e de Rodnei Nascimento. São Paulo: Martins Fontes, 2002a.

. La Necesidad de Revisión de la Izquierda. Traducción de Manuel Jiménez Redondo. Madrid: Editorial Tecnos, 1991.

- A Inclusão do Outro: Estudos de Teoria Política. Tradução de George Sperber e de Paulo Astor Soethe. São Paulo: Edições Loyola, 2002b.

- La Constelación Posnacional: Ensayos Políticos. Traducción de Pere Fabra Abat, de Daniel Gamper Sachse y de Luis Pérez Díaz. Barcelona: Ediciones Paidós, 2000.

. Europe: the Faltering Project. Translated by Ciaran Cronin. Cambridge: Polity Press, 2009.

HARRINGTON, Michael. "Socialismo: Passado e Futuro", In: HOOK, Sidney, et al. A Social-Democracia nos Estados Unidos. Tradução de Rodrigo Sardenberg. Brasília: Instituto Teotônio Vilela, 1999, p. 87-144.

HARVEY, David. O Neoliberalismo: História e Implicações. Tradução de Adail Sobral e de Maria Stela Gonçalves. São Paulo: Edições Loyola, 2008. 
HAYEK, Friedrich August von. O Caminho da Servidão. 4ª Edição. Tradução e Revisão de Anna Maria Capovilla, de José Ítalo Stele e de Liane de Morais Ribeiro. Rio de Janeiro: Instituto Liberal, 1987.

- Arrogância Fatal: os Erros do Socialismo. Tradução de Ana Maria Capovilla e de Candido Mendes Prunes. Porto Alegre: Editora Ortiz, 1995.

- Direito, Legislação e Liberdade: Uma Nova Formulação dos Princípios Liberais de Justiça e de Economia Política (Vol. II) - a Miragem da Justiça Social. Tradução de Henry Maksoud. São Paulo: Visão, 1985.

HICKS, Alexander. Social Democracy and Welfare Capitalism: A Century of Income Security Politics. Ithaca \& London: Cornell University Press, 1999.

HOOK, Sidney. "O Sentido Moral da Social-Democracia", p. 13-38. In: HOOK, Sidney, et al. A Social-Democracia nos Estados Unidos. Tradução de Rodrigo Sardenberg. Brasília: Instituto Teotônio Vilela, p. 1999.

HONNETH, Axel. Reificación: Un Estudo en la Teoría del Reconhecimento. Traducido por Graciela Calderón. Buenos Aires: Katz, 2007.

KATZ, Michael B. Improving Poor People: the Welfare State, the "Underclass" and Urban Schools as History. Princeton: Princeton University Press, 1995.

KOLAKOWSKI, Leszek. "O Desafio Social-Democrata", p. 39-49. In: HOOK, Sidney, et al. A Social-Democracia nos Estados Unidos. Tradução de Rodrigo Sardenberg. Brasília: Instituto Teotônio Vilela, 1999. 
MACPHERSON, C. B. Ascensão e Queda da Justiça Econômica e Outros Ensaios: o Papel do Estado, das Classes e da Propriedade na Democracia do Século XX. Tradução de Luiz Alberto Monjardim. Rio de Janeiro: Paz e Terra, 1991.

. A Democracia Liberal: Origens e Evolução. Tradução de Nathanael C. Caixeiro. Rio de Janeiro: Zahar Editores, 1978.

MCCARTHY, Thomas. "Reflexión sobre la Racionalización en la Teoría de la Acción Comunicativa", p. 121-149. In: GIDDENS, Anthony et al. Habermas y la Modernidad. Traducción de Francisco Rodríguez Martins. Madrid: Ediciones Cátedra, 2001.

MILIBAND, Ralph. O Estado na Sociedade Capitalista. Tradução de Fanny Tabak. Rio de Janeiro: Zahar Editores, 1972.

NOZICK, Robert. Anarquia, Estado e Utopia. Tradução de Raul Jungmann. Rio de Janeiro: Zahar, 1991.

OFFE, Claus. Problemas Estruturais do Estado Capitalista. Tradução de Bárbara Freitag. Rio de Janeiro: Tempo Brasileiro, 1984.

. Capitalismo Desorganizado: Transformações Contemporâneas do Trabalho e da Política. Tradução de Wanda Caldeira Brandt. São Paulo: Editora Brasiliense, 1989.

. Trabalho 8 Sociedade: Problemas Estruturais e Perspectivas para o Futuro da Sociedade do Trabalho (Vol. II) - Perspectivas. Tradução de Gustavo F. Bayer e de Margit Martincic. Rio de Janeiro: Tempo Brasileiro, 1991. 
. "Ungovernability: on the Renaissance of Conservative Theories of Crisis", p. 64-97. In: HABERMAS, Jürgen (Ed.). Observations on "The Spiritual Situation of the Age". Traduction by Andrew Buchwalter. Cambridge: The MIT Press, 1987.

POULANTZAS, Nicos. O Poder, o Estado, o Socialismo. Rio de Janeiro: Graal, 1981.

RAWLS, John. Uma Teoria da Justiça. Tradução de Almiro Pisetta e de Lenita Maria Rímoli Esteves. São Paulo: Martins Fontes, 2002.

. Justiça como Eqüidade: Uma Reformulação. Tradução de Cláudia Berliner. São Paulo: Martins Fontes, 2003.

WHITE, Stephen K. Razão, Justiça e Modernidade: a Obra Recente de Jürgen Habermas. Tradução de Márcio Pugliesi. São Paulo: Ícone, 1995. 